Check for updates

Cite this: RSC Adv., 2018, 8, 12344

Received 26th January 2018

Accepted 5th March 2018

DOI: $10.1039 / c 8 r a 00815 a$

rsc.li/rsc-advances

\title{
Catalytic alcoholysis of alkaline extracted lignin for the production of aromatic esters over $\mathrm{SO}_{4}{ }^{2-}$ I $\mathrm{ZrO}_{2}$-ATP
}

\begin{abstract}
Zhen Wu, (D) ab Jun Zhang, ${ }^{a}$ Qingqing Pan, ${ }^{a}$ Xun Li, ${ }^{a}$ Yu Zhang ${ }^{a}$ and Fei Wang ${ }^{\star a}$
An efficient process for the depolymerization of alkaline extracted lignin (AEL) using attapulgite (ATP)supported solid catalysts in ethanol was developed in this work. Different ATP-supported catalysts were prepared and used to catalyze the depolymerization of the lignin AEL. The results demonstrated that the addition of ATP-supported catalysts was favorable for controlling the distribution of valuable depolymerization products. The optimal solid catalyst $\mathrm{SO}_{4}{ }^{2-} / \mathrm{ZrO}_{2}-\mathrm{ATP}$ (Cat 2) exhibited high catalytic activity and selectivity, which showed a $78.6 \%$ conversion of AEL and a $29.4 \%$ selectivity to ethyl ferulate (ethyl 4-hydroxy-3-methoxycinnamate) with a catalyst/AEL ratio of $1: 1$ at $200{ }^{\circ} \mathrm{C}$ for $120 \mathrm{~min}$. The catalyst could be reused and its catalytic activity did not obviously decreased after 6 successive runs. Particularly, a plausible mechanism involving esterification, hydrogenation, and dehydration for the production of aromatic esters from AEL depolymerization over $\mathrm{SO}_{4}{ }^{2-} / \mathrm{ZrO}_{2}-\mathrm{ATP}$ in ethanol was also proposed.
\end{abstract}

\section{Introduction}

Lignin is a highly cross-linked macromolecule which consists of various oxygen and carbon bridges between alkylated methoxyl-phenol rings. Based on its phenolic functionalities and properties, lignin offers possibilities for high value-added renewable products applications. ${ }^{1}$ Lignin has been gradually generated as a byproduct in bioethanol production and the pulp/paper industry. However, this readily available lignin is a rich source of aromatic monomers and hence, if depolymerized efficiently, it can produce value-added chemicals and fuels. ${ }^{2}$ In fact, it has been estimated that less than $2 \%$ of lignin byproducts from the paper industry are used for specialty products. ${ }^{3}$ Therefore, developing efficient technologies for the high value utilization of lignin is crucially important and imperative. ${ }^{4}$

As a natural amorphous three-dimensional polymer consisting mainly of methoxylated phenylpropane units, ${ }^{2,5}$ lignin is linked to other main components, such as cellulose and hemicellulose, in a variety of ways, including hydrogen, ester, and covalent bonds. ${ }^{6}$ Depolymerization of lignin is the key step towards making lignin cost-effective as a raw material, ${ }^{7}$ but its

${ }^{a}$ College of Chemical Engineering, Nanjing Forestry University, Jiangsu Provincial Key Lab for Chemistry and Utilization of Agro-forest Biomass, Jiangsu Key Lab of Biomass-Based Green Fuels and Chemicals, Jiangsu Co-Innovation Center of Efficient Processing and Utilization of Forest Resources, Nanjing 210037, China. E-mail: hgwf@njfu.edu.cn

bJiangsu Key Laboratory for Biomass-based Energy and Enzyme Technology, School of Chemistry and Chemical Engineering, Huaiyin Normal University, Huaian 223300, China highly random and branched three-dimensional polyphenolic structure leads to its resistance to depolymerization. ${ }^{8}$

Various catalytic depolymerization methods have been used to depolymerize lignin into monomeric compounds and reduction depolymerization with the existence of hydrogen or a hydrogen donner, e.g. methanol, ethanol and i-propanol, is considered as a splendid process. Chen et al. ${ }^{9}$ use mesoporous SBA-15 catalysts to depolymerize hydrolyzed lignin and eliminate char in ethanol and the results demonstrate that both catalyst and ethanol play important roles in suppressing the repolymerization reaction. Yan et al. ${ }^{10}$ have reported the depolymerization of kraft lignin in supercritical ethanol on a $\mathrm{MoC}_{1-x} / \mathrm{Cu}-\mathrm{MgAlO}_{z}$ composite catalyst and a yield of aromatic compounds of $575 \mathrm{mg} \mathrm{g}^{-1}$ lignin is achieved at $330{ }^{\circ} \mathrm{C}$. Hidajat et al. ${ }^{11}$ report the base-catalyzed depolymerization of lignin in supercritical methanol and they find that the most abundant monomers produced are methoxylated benzene and toluene species because of the unique $O$-alkylation ability of supercritical methanol. Kim et al. ${ }^{12}$ illustrate that lignin can be selectively degraded to alkylated phenols efficiently in supercritical $t$-BuOH as the $M_{\mathrm{w}}$ of lignins decrease after a supercritical $t$-BuOH treatment, which demonstrating the effectiveness of this method for lignin depolymerization.

Heterogeneous catalysts are currently used extensively in lignin depolymerization, which are particularly suited for large-scale industrial operations due to their many advantages over homogeneous catalysts. The products can be easily separated to allow recovery and reuse of solid catalysts..$^{13}$ There are many literatures about heterogeneous catalysts, including 
metal sulfide, ${ }^{\mathbf{1 4}}$ metal phosphide, ${ }^{\mathbf{1 5}}$ metal carbide, ${ }^{\mathbf{1 6}, 17}$ and metal nitride, ${ }^{\mathbf{1 8}, 19}$ etc. Although these materials have showed good performance in catalysis, the precursors acting as nitrogen and/or carbon sources are expensive. Moreover, the preparation processes of the precursors are complicated.

Attapulgite (ATP) is a mesoporous clay phyllosilicate mineral, which has an ideal formula $\left(\mathrm{Mg}, \mathrm{Al}_{4}\right)_{4} \mathrm{Si}_{8} \mathrm{O}_{20}(\mathrm{OH})_{2}\left(\mathrm{H}_{2} \mathrm{O}\right)_{4} \cdot 4 \mathrm{H}_{2} \mathrm{O}$ and $\mathrm{Mg} / \mathrm{Al}$ ratio $\leq 1{ }^{20}$ There are significant ATP reserves in various countries such as China, the US, and Spain. ${ }^{21}$ The high surface area, porosity, thermal resistance, and fibrous morphology of ATP provide much potential for diverse applications such as catalyst supports, nanocomposites, and environmental absorbents. ${ }^{22}$ Miao et $a .^{23}$ report that rhodium nanoparticles can be supported on ATP via an ionic liquid (1,1,3,3-tetramethylguanidine lactate, $\left.\mathrm{TMG}^{+} \mathrm{L}^{-}\right)$ and the resulting catalyst is active and stable for hydrogenation of cyclohexene. More recently, a new type of hybrid material has been fabricated from the hybridization of metal-organic framework HKUST-1 and ATP whose surface areas are even higher than that of pure HKUST-1. Such hybrid materials exhibit good catalytic activity in the ring-opening reaction of styrene oxide. ${ }^{21}$ Zirconia, with high catalytic activity, good thermal and chemical stabilities, is commonly used as catalyst supporting material. Meanwhile, coke which may cover active sites is hardly formed on $\mathrm{ZrO}_{2} \cdot{ }^{24}$ Zirconium oxide treated with sulfuric acid exhibits a strong acidity. ${ }^{25}$

To depolymerize lignin into high-valued monomeric compounds, a novel method was herein developed in this work, in which the advantages of solid catalysts and clay materials are combined to develop a new type of low-cost catalyst with high catalytic activity and selectivity for lignin depolymerization. The objective of the present study is to explore process parameters for the effective depolymerization of lignin over ATP-supported catalysts in alcohols. For this purpose, the effects of lignin source, solvent, composition of catalysts, and reaction conditions were examined in detail. Furthermore, we also performed studies toward the stability of the catalysts prepared. In the proposed strategy, we designed the reaction routes of directional conversion to aromatic esters from lignin over ATP-supported catalysts and the reaction mechanism was also discussed.

\section{Materials and methods}

\subsection{Chemicals and materials}

The lignocellulosic materials harvested in the northern part of China were cut into 3-5 mm in length, screened $(1 \mathrm{~mm} \times 1 \mathrm{~mm}$ sieve), washed with deionized water, and air-dried. The ATP mineral was friendly provided by Xuyi Oubaite Clay Material Co. Ltd. (Huaian, China). The ethanol and sulphuric acid were purchased from Nanjing chemical reagent Co., LTD. The metal precursors $\quad\left(\mathrm{H}_{32} \mathrm{Mo}_{7} \mathrm{~N}_{6} \mathrm{O}_{28}, \quad \mathrm{Co}\left(\mathrm{NO}_{3}\right)_{2} \cdot 6 \mathrm{H}_{2} \mathrm{O}, \mathrm{H}_{6} \mathrm{O}_{41} \mathrm{SiW}_{12}\right.$, $\mathrm{ZrOCl}_{2} \cdot 8 \mathrm{H}_{2} \mathrm{O}$ ) were purchased from Sinopharm Chemical Reagent Co. Ltd. (Shanghai, China) and used without further purification.

\subsection{Preparation of alkaline extracted lignin}

Alkaline extracted lignin (AEL) was obtained from mild alkali cooking of as-prepared lignocellulosic material. In brief, a $10 \mathrm{~g}$ material was added to $2.5 \%$ sodium hydroxide solution at a liquid/solid ratio of $10: 1(\mathrm{v} / \mathrm{w})$ in a three-necked flask and then heated to $105{ }^{\circ} \mathrm{C}$ for $2 \mathrm{~h}$ with stirring at $200 \mathrm{rpm}$. The mixture was filtrated at a high temperature and washed with hot distilled water. The filtrate was neutralized to $\mathrm{pH} 3.5$ with $20 \%$ sulfuric acid at $60{ }^{\circ} \mathrm{C}$ for $30 \mathrm{~min}$. The precipitate was separated by centrifugation and then dried at $50{ }^{\circ} \mathrm{C}$ for $72 \mathrm{~h}$ in a vacuum oven, sieved to particle size smaller than 40 mesh $(<0.425 \mathrm{~mm})$ prior to the depolymerization experiments.

\subsection{Catalyst preparation and characterization}

The ATP mineral was firstly treated with $0.5 \mathrm{wt} \% \mathrm{HNO}_{3}$ to activate its surface to get an activated ATP aqueous dispersion, whose solid content could be controlled in the range of 15-25\%. The suspension was stirred at room temperature for $8 \mathrm{~h}$, filtered and washed to neutral, dried at $105{ }^{\circ} \mathrm{C}$ for $12 \mathrm{~h}$, and sieved to particle size smaller than 100 mesh $(<0.154 \mathrm{~mm})$.

The preparation procedure of ATP-supported Co-Mo catalyst, for example, could be described as follows: $20 \mathrm{~g}$ of ATP was added into $60 \mathrm{~mL}$ deionized water in a round-bottom flask and stirred at $45{ }^{\circ} \mathrm{C}$. $1.85 \mathrm{~g}$ of $\mathrm{H}_{32} \mathrm{Mo}_{7} \mathrm{~N}_{6} \mathrm{O}_{28}$ and $4.93 \mathrm{~g}$ of $\mathrm{Co}\left(\mathrm{NO}_{3}\right)_{2} \cdot 6 \mathrm{H}_{2} \mathrm{O}$ were added into the above ATP/deionized water suspension, adjusted to $\mathrm{pH}$ 9-10 with ammonia, stirred at $85{ }^{\circ} \mathrm{C}$ for $6 \mathrm{~h}$, filtered immediately, dried at $105^{\circ} \mathrm{C}$ for $12 \mathrm{~h}$ and then calcined at $500{ }^{\circ} \mathrm{C}$ for $3 \mathrm{~h}$, sieved to particle size smaller than 100 mesh, and denoted as Co-Mo/ATP. The procedure for preparing ATP-supported silicotungstic acid catalyst was same to that of Co-Mo/ATP, but deionized water was substituted by $50 \%(\mathrm{v} / \mathrm{v})$ ethanol aqueous solution and calcined at $200{ }^{\circ} \mathrm{C}$ for $5 \mathrm{~h}$, sieved to particle size smaller than $100 \mathrm{mesh}$, and denoted as STA/ATP.

The procedure for preparation of $\mathrm{SO}_{4}{ }^{2-} / \mathrm{ZrO}_{2}$-ATP was as follows: $50 \mathrm{~g}$ of ATP was added into $200 \mathrm{~mL}$ deionized water in a round-bottom flask, $10 \mathrm{~g}$ of $\mathrm{ZrOCl}_{2} \cdot 8 \mathrm{H}_{2} \mathrm{O}$ was added into the suspension and stirred at $45^{\circ} \mathrm{C}$ for $2 \mathrm{~h}$, adjusted to $\mathrm{pH}$ 9-10 with ammonia, aged at room temperature for $24 \mathrm{~h}$, filtered and washed to neutral, dried at $105{ }^{\circ} \mathrm{C}$ for $12 \mathrm{~h}$ and ground, then it was impregnated in $2 \mathrm{~mol} \mathrm{~L}^{-1} \mathrm{H}_{2} \mathrm{SO}_{4}$ for $4 \mathrm{~h}$, filtered and dried at $105{ }^{\circ} \mathrm{C}$ for $12 \mathrm{~h}$, then calcined at $500{ }^{\circ} \mathrm{C}$ for $3 \mathrm{~h}$, and sieved to particle size smaller than 100 mesh. Thereafter, $\mathrm{SO}_{4}{ }^{2-} / \mathrm{ZrO}_{2}-\mathrm{ATP}$ (Cat 1) was obtained. $\mathrm{SO}_{4}{ }^{2-} / \mathrm{ZrO}_{2}$-ATP (Cat 2) and $\mathrm{SO}_{4}{ }^{2-} / \mathrm{ZrO}_{2}$ ATP (Cat 3) were prepared through the same procedure with different $\mathrm{ZrOCl}_{2} \cdot 8 \mathrm{H}_{2} \mathrm{O}$ mass of $25 \mathrm{~g}$ and $50 \mathrm{~g}$, respectively. The procedure for preparing $\mathrm{SO}_{4}{ }^{2-} / \mathrm{ZrO}_{2}$ and $\mathrm{ZrO}_{2}$-ATP were also same to that of $\mathrm{SO}_{4}{ }^{2-} / \mathrm{ZrO}_{2}$-ATP (Cat 1 ), but no ATP was impregnated for $\mathrm{SO}_{4}{ }^{2-} / \mathrm{ZrO}_{2}$ or without loading of $\mathrm{SO}_{4}{ }^{2-}$ for $\mathrm{ZrO}_{2}$-ATP. All prepared catalysts were stored in a vacuum dryer before use in any reaction.

X-ray photoelectron spectra (XPS), Brunauer-Emmett-Teller (BET), Fourier transform infrared spectroscopy (FTIR), scanning electron microscopy (SEM), and transmission electron microscopy (TEM) were used to detect and characterize the structural characteristics and properties of the as-prepared catalysts. XPS were recorded with a Kratos Axis Ultra DLD spectrometer, $\mathrm{Al} \mathrm{K \alpha}$ radiation as the excitation source, and the X-ray power supply was run at $15 \mathrm{kV}$ and $10 \mathrm{~mA}$. Nitrogen gas adsorption desorption 
isotherms were measured at $77 \mathrm{~K}$ using a Quantachrome Autosorb $\mathrm{iQ}_{2}$ instrument. The specific surface area was estimated by the multipoint BET method using the adsorption data. SEM and TEM images were recorded on a JSM-7600F and JEM-1400 instrument, respectively. FTIR spectrum was obtained on a Nicolet 380 FTIR spectrometer using $\mathrm{KBr}$ discs in the range of $4000-400 \mathrm{~cm}^{-1}$.

\subsection{Depolymerization of the lignin}

The depolymerization reactions were carried out in a $50 \mathrm{~mL}$ micro autoclave equipped with a temperature controller and a pressure sensor. For a typical experiment, $0.5 \mathrm{~g}$ of AEL, $0.25 \mathrm{~g}$ of catalyst, and $15 \mathrm{~mL}$ of ethanol were loaded into the autoclave, purged with high-purity nitrogen for three times, then heated to the desired temperature and kept for the desired reaction time. After the reaction, the autoclave was cooled down to room temperature by ice-bath. After releasing the gas, the reaction mixture was filtrated. The solid residue was washed with ethanol and water, dried at $105{ }^{\circ} \mathrm{C}$ for $12 \mathrm{~h}$ and then weighed and the weight loss rate was calculated as conversion of AEL. The filtrate was collected for gas chromatography-mass spectrometry (GC-MS) analysis.

\subsection{Products analysis}

The organic phase containing the products was injected neatly to a GC-MS system (Agilent GC7890A/MSD5975C) for product qualitative analysis. GC-MS was equipped with EI source, DB-5 capillary column $(30 \mathrm{~m} \times 0.25 \mathrm{~mm} \times 0.25 \mu \mathrm{m})$ and NIST05 MS data base. An inlet temperature of $290^{\circ} \mathrm{C}$, a He gas flow rate of $20 \mathrm{~mL} \mathrm{~min} \mathrm{~min}^{-1}$ and a flow split-ratio of $10: 1$ were used for the GC analysis. A heating schedule for the column was pre-set as: remained at $50{ }^{\circ} \mathrm{C}$ for $5 \mathrm{~min}$, increased to $280{ }^{\circ} \mathrm{C}$ at a rate of $5{ }^{\circ} \mathrm{C} \min ^{-1}$ and then remained for $5 \mathrm{~min}$. The solvent delay was set as 2 min for MS detector. Each experiment was conducted at least three times under the same conditions, and their average values were reported.

\section{Results and discussion}

\subsection{Catalyst characterization}

In order to illustrate the characteristics of the ATP-supported catalysts, a series of tests were carried out. The as-prepared catalysts were characterized by XPS, and the survey spectra of all ATPs were shown in Fig. 1. It can be seen from ATP curve that the predominant peaks at $712 \mathrm{eV}, 532 \mathrm{eV}, 285 \mathrm{eV}, 103 \mathrm{eV}, 75 \mathrm{eV}$, and $57 \mathrm{eV}$ are attributed to $\mathrm{Fe}, \mathrm{O}, \mathrm{C}, \mathrm{Si}, \mathrm{Al}$, and $\mathrm{Mg}$ species. XPS analysis showed that the $\mathrm{Fe}, \mathrm{O}, \mathrm{C}, \mathrm{Si}, \mathrm{Al}, \mathrm{Mg}$, and $\mathrm{N}$ mass contents on the surface of ATP were $6.48 \%, 44.84 \%, 22.87 \%$, $18.32 \%, 5.16 \%, 2.06 \%$, and $0.27 \%$, respectively. As shown in Fig. 1, all the target elements were successfully loaded onto the surface of ATP (see the curves of $\mathrm{SO}_{4}{ }^{2-} / \mathrm{ZrO}_{2}$-ATP, $\mathrm{ZrO}_{2}$-ATP, STA/ATP and Co-Mo/ATP in Fig. 1).

The specific surface area, pore size, and pore volume of the ATP-supported catalysts are listed in Table 1. As shown, the specific surface area decreased obviously after being modified by Co and Mo or STA. One can speculate that in the co-

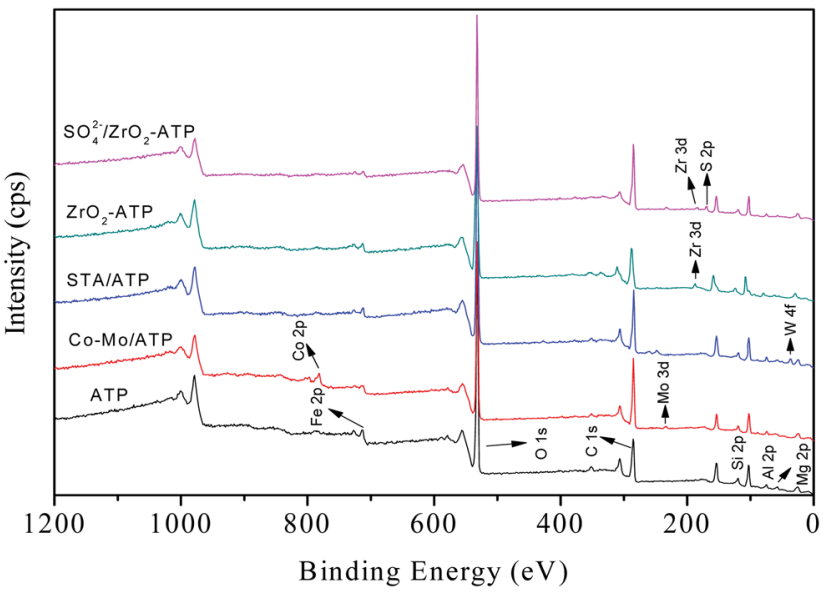

Fig. 1 XPS full-scan spectra of ATP and ATP-supported catalysts.

precipitation process of catalyst preparation, the metal oxides dispersed on the surface of the catalyst leading to the decrease of the specific surface area and a part of metal oxides entered into the pore leading to the decrease of the pore volume. Among all of the as-prepared catalysts, $\mathrm{ZrO}_{2}$-ATP was the only one not to present a decline in specific surface area compared to ATP. This can be attributed to the approximate specific surface area and pore size of $\mathrm{ZrO}_{2} \cdot{ }^{26,27}$ However, it is worth noting that the specific surface area and pore volume of $\mathrm{ZrO}_{2}$-ATP decrease dramatically after $\mathrm{SO}_{4}{ }^{2-}$ loading. The possible reasons may be that fibrous bundles are disaggregated initially, and then the octahedral cations $\left(\mathrm{Mg}^{2+}\right.$ and $\left.\mathrm{Al}^{3+}\right)$ are dissolved. ${ }^{28}$

\subsection{Catalytic activity}

Inspired by previous studies, ${ }^{15,29,30}$ ATP-supported catalysts were prepared to catalyze the depolymerization of AEL. As a hydrogen donor, alcohols used in lignin depolymerization can suppress the condensation of the phenolic intermediates. ${ }^{10}$ In this paper, the catalytic activities of the ATP-supported catalysts were tested at $225{ }^{\circ} \mathrm{C}$ in ethanol.

The main products obtained from AEL of corncob in the absent/presence of ATP-supported catalysts were verified to be compounds 1-18 as shown in Table 2. The monomeric compounds produced mainly consisted of phenol and its derivatives, including phenols (compounds 1-8), aldehydes (compound 9), esters (compounds 10-15), ethers (compounds

Table 1 Physical characteristics of the ATP-supported catalysts

\begin{tabular}{lcll}
\hline Catalyst & & $\begin{array}{l}\text { Pore size } \\
(\mathrm{nm})\end{array}$ & $\begin{array}{l}\text { Pore volume } \\
\left(\mathrm{cm}^{3} \mathrm{~g}^{-1}\right)\end{array}$ \\
\hline $\mathrm{ATP}$ & 221.583 & 1.178 & 0.252 \\
$\mathrm{Co}-\mathrm{Mo} / \mathrm{ATP}$ & 208.320 & 2.419 & 0.249 \\
$\mathrm{STA} / \mathrm{ATP}$ & 171.800 & 1.176 & 0.227 \\
$\mathrm{ZrO}_{2}$-ATP & 228.559 & 1.410 & 0.296 \\
$\mathrm{SO}_{4}{ }^{2-} / \mathrm{ZrO}_{2}$ & 198.268 & 3.627 & 0.174 \\
$\mathrm{SO}_{4}{ }^{2-} / \mathrm{ZrO}_{2}$-ATP $($ Cat 1) & 109.084 & 2.419 & 0.172 \\
$\mathrm{SO}_{4}{ }^{2-} / \mathrm{ZrO}_{2}$-ATP (Cat 2) & 50.902 & 4.543 & 0.096 \\
$\mathrm{SO}_{4}{ }^{2-} / \mathrm{ZrO}_{2}$-ATP (Cat 3) & 80.075 & 3.169 & 0.077
\end{tabular}


16 and 17), and acids (compound 18). As expected, catalysts showed a large effect on the distribution of depolymerization products. In the absence of catalyst, only 34.6\% AEL conversion was obtained (Fig. 2) and the products were complicated and fragmented (Fig. 3(a)). When ATP-supported catalysts were added, AEL conversions were improved to varying degrees and the products distribution changed apparently. A high conversion of AEL (82.3\%) was found for the addition of ATP, but the products were still fragmented. Relatively high content of ethyl hydroferulate (ethyl 3-(4-hydroxy-3-methoxyphenyl) propionate, compound 11) was obtained in the presence of Co-Mo/ATP, however, conversion of AEL was increased slightly. The addition of STA/ATP or $\mathrm{ZrO}_{2}$-ATP made the products more dispersed. However, it was worth noting that the contents of esters (compounds 10-15) increased significantly after $\mathrm{SO}_{4}{ }^{2-}$ loading onto $\mathrm{ZrO}_{2}$. The esterification reaction between ethanol and decomposition products of phenolic oligomers or monomers may be the main contributor to the increase in esters. In addition, previous studies demonstrate that $\mathrm{SO}_{4}{ }^{2-} / \mathrm{ZrO}_{2}$ shows strong acidity and catalytic activity for lignin depolymerization. For instance, $\mathrm{CuO} / \mathrm{SO}_{4}{ }^{2-} / \mathrm{ZrO}_{2}$ has been explored for the hydrogenolysis of soda lignin by Zhang et al. ${ }^{31}$ who report that the main effect of $\mathrm{SO}_{4}{ }^{2-} / \mathrm{ZrO}_{2}$ is cleaving the $\beta-O-4$ linkages, and $\mathrm{CuO}$ is cracking the methoxy groups. Moreover, $\mathrm{SO}_{4}{ }^{2-} / \mathrm{ZrO}_{2}$ with higher acidity is favorable for dehydration and esterification reactions. ${ }^{32}$

When catalyst $\mathrm{SO}_{4}{ }^{2-} / \mathrm{ZrO}_{2}$-ATP (Cat 1 ) was added to the above-mentioned reaction system, a $81.4 \%$ conversion of AEL was achieved and the products distribution changed apparently (Fig. 3(b)). The contents of aromatic esters increased steeply and a $22.5 \%$ selectivity was obtained for ethyl ferulate (ethyl 4hydroxy-3-methoxycinnamate, compound 10, peak at 38.103'), which is a noteworthy compound, not only because of its flavor characteristics but also its antioxidant and functional properties and is currently used as a sun screening agent in commercial sunscreen blends. ${ }^{33,34}$ Much larger amounts of aromatic esters were produced by the addition of $\mathrm{SO}_{4}{ }^{2-} / \mathrm{ZrO}_{2}$ ATP, suggesting that the depolymerization reaction of AEL appeared directional conversion over $\mathrm{SO}_{4}{ }^{2-} / \mathrm{ZrO}_{2}$-ATP. This can be attributed to the enhancement of porosity and the excellent properties for the selective hydrogenation of the acidified ATPsupported catalyst. ${ }^{35,36}$ Among all ATP-supported catalysts prepared, $\mathrm{SO}_{4}{ }^{2-} / \mathrm{ZrO}_{2}$-ATP with high catalytic activity and selectivity was selected for further investigations.

To get more insight into the catalyst $\mathrm{SO}_{4}{ }^{2-} / \mathrm{ZrO}_{2}$-ATP (Cat 1), FTIR spectrum was recorded (Fig. 4). The peak at $3615 \mathrm{~cm}^{-1}$ is assigned to stretching vibration of $\mathrm{Al}-\mathrm{OH}$ and $(\mathrm{Al}-\mathrm{Fe})-\mathrm{OH}$, which is the character of ATP. The peak at $3411 \mathrm{~cm}^{-1}$ is attributed to hydroxyl stretching vibration of coordinated water of ATP. The peak located at $1638 \mathrm{~cm}^{-1}$ can be assigned to an $\mathrm{OH}_{2}$ bending vibration. The $\mathrm{Si}-\mathrm{O}-\mathrm{Si}$ stretching band appears at $1020 \mathrm{~cm}^{-1} \cdot .^{28,37}$ The absorbance peaks at $1155 \mathrm{~cm}^{-1}$ and $1078 \mathrm{~cm}^{-1}$, representative of the symmetric stretching vibration of $\mathrm{O}-\mathrm{S}-\mathrm{O},{ }^{38}$ is also observed in the spectrum, verifying $\mathrm{SO}_{4}{ }^{2-}$ has been successfully grafted onto ATP to form $\mathrm{SO}_{4}{ }^{2-} / \mathrm{ZrO}_{2}-\mathrm{ATP}$. The changes of morphology and structure of ATP after modification were also examined by SEM and TEM. It is obvious from
Fig. 5 that ATP is well-crystallized and an individual crystalline rod is about $500 \mathrm{~nm}$ in length and $50 \mathrm{~nm}$ in diameter. Although the surface of the fibrous bundles was partially covered and disaggregated, significant changes in morphology and structure of ATP were not observed and large enough surface area and pore size were maintained after modification, providing much potential for the adequate contact and adsorption of reactants during lignin depolymerization.

\subsection{Effect of lignin source}

The structure and properties of different varieties of lignin vary with extraction method, plant type, environmental factors, and even genotype. ${ }^{39}$ Thus, the structural characteristics of the six kinds of AEL used in this study (corncob lignin: CCL, corn straw lignin: CSL, rice straw lignin: RSL, wheat straw lignin: WSL, poplar lignin: PL, and bamboo lignin: BL) were comparatively analysed before investigating the distributions of aromatic esters in lignin alcoholysis products.

It was clearly observed from Fig. 6 that all the lignin samples exhibited the expected functional groups: hydrogen bonded $\mathrm{O}-\mathrm{H}$ stretching vibration at $3421 \mathrm{~cm}^{-1}, \mathrm{C}-\mathrm{H}\left(\mathrm{CH}_{3}, \mathrm{CH}_{2}\right)$ stretching vibration at $2933 \mathrm{~cm}^{-1}, \mathrm{C}=\mathrm{O}$ stretching vibration (conjugated ketone, carbonyl, and ester groups) at $1686 \mathrm{~cm}^{-1}$, aromatic skeletal vibrations at 1600, 1510 and $1421 \mathrm{~cm}^{-1}, \mathrm{C}-\mathrm{H}$ deformation vibration at $1463 \mathrm{~cm}^{-1}$ (connected to benzene ring or in $\mathrm{O}-\mathrm{CH}_{3}$ ), vibration at $1328 \mathrm{~cm}^{-1}$ from syringyl rings, $\mathrm{C}=\mathrm{O}$ stretching vibration at $1243 \mathrm{~cm}^{-1}$ from guaiacyl rings. Overall, the CCL, CSL, RSL, WSL, and BL had more strong absorption peaks at 1157,1123 , and $836 \mathrm{~cm}^{-1}$, those are the typical signal of herbaceous lignin (consist of GSH units).

The effect of lignin source on AEL depolymerization was investigated and the results in the comparison of the conversion and selectivity of the six different lignin sources were shown in Fig. 7. A lower conversion of lignin and negligible amount of ethyl ferulate (EF) were obtained from the poplar lignin, indicating that the poplar lignin has more recalcitrant properties. Peng et al. ${ }^{40}$ report that a minor amount of $\mathrm{H}$ units is observed in poplar lignin sample, which is connected to $\mathrm{G}$ and $\mathrm{S}$ units by multiple ester linkages, suggesting a more obstinate and stable structure compared to herbaceous lignin that consist of GSH units. Meanwhile, ferulic acid is commonly found in commelinid plants, mostly in the trans-isomeric form, and esterified with the specific polysaccharides. ${ }^{\mathbf{4 1}}$ Hence, the lower content of ferulic acid in poplar lignin may be the main contributor to the low selectivity to ethyl ferulate. Among all AELs prepared, CCL exhibited superior selectivity to ethyl ferulate as compared to other herbaceous lignins was selected for the following study.

\subsection{Effects of solvent and composition of catalysts}

The effects of solvent and composition of catalysts on AEL of corncob depolymerization were examined at $225{ }^{\circ} \mathrm{C}$ for a reaction time of 120 min using ATP-supported catalysts $\mathrm{SO}_{4}{ }^{2-} / \mathrm{ZrO}_{2}$ ATP with different $\mathrm{ZrO}_{2}$-to-ATP mass ratios in methanol, ethanol, and i-propanol, respectively. Fig. 8 shows the conversion (a) and selectivity (b) of the lignin depolymerization over different composition of catalysts in low mass molecule 
Table 2 Products distribution for depolymerization of AEL over ATP-supported catalysts ${ }^{a}$

\section{Catalyst}

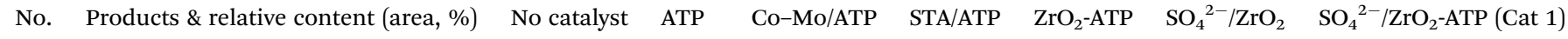

1<smiles>Oc1ccccc1</smiles><smiles>COc1ccccc1O</smiles>

3<smiles>CCc1ccc(O)cc1</smiles>

4<smiles>CCc1ccc(O)c(OC)c1</smiles>

5<smiles>C/C=C/c1ccc(O)c(OC)c1</smiles>

6<smiles>C=Cc1ccc(O)c(OC)c1</smiles>

7<smiles>C=CC(CC)=C(O)C(=C)OC</smiles>

8<smiles>C=CCc1cc(OC)c(Br)c(OC)c1</smiles>

3.09<smiles>C=Cc1ccc(O)c(OC)c1</smiles>

3.25<smiles>CCOC(=O)/C=C/c1ccc(Cl)c(OC)c1</smiles>

11<smiles>CCOC(=O)CCc1ccc(O)c(OC)c1</smiles>

12<smiles>COC(=O)Cc1ccc(O)c(OC)c1</smiles>

0.44

1.39

2.81

5.31

10

1.32
10.43

13.23

$1.08 \quad 2.77$

2.83

1.15

2.08

4.49

$1.66 \quad 7.06$

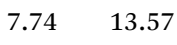

$3.07 \quad 1.53$

3.26

2.28

7.24
0.61

2.28

6.36

5.42

0.65
0.77

0.62

22.51

.12

.79 
Table 2 (Contd.)

Catalyst

No. Products \& relative content (area, \%) No catalyst $\quad$ ATP $\quad$ Co-Mo/ATP $\quad$ STA/ATP $\quad \mathrm{ZrO}_{2}-\mathrm{ATP} \quad \mathrm{SO}_{4}{ }^{2-} / \mathrm{ZrO}_{2} \quad \mathrm{SO}_{4}{ }^{2-} / \mathrm{ZrO}_{2}-\mathrm{ATP}(\mathrm{Cat} 1)$

13<smiles>CCOC(=O)c1ccc(O)c(OC)c1</smiles>

14

15

16

17<smiles>CCCCCCCCCCCCCCC(C)CCC</smiles><smiles>CCOC(=O)CCC(C)=O</smiles><smiles>CCOc1ccccc1</smiles>

18<smiles>CCOc1ccc(CC)cc1</smiles><smiles>COc1cc(CC(=O)O)ccc1O</smiles>

1.94

2.84

-

-

$-$
0.56

$3.84 \quad 5.80$

- -

$-\quad-$

1.95

1.02

-

1.17 alcohols. As expected, the conversion and selectivity were increased significantly by the use of $\mathrm{SO}_{4}{ }^{2-} / \mathrm{ZrO}_{2}$-ATP in all alcohols. In addition, different alcohol showed the different alcoholysis ability. In the case of ethanol, conversions of lignin reached $81.4 \%, 72.5 \%$, and $75.9 \%$, respectively, which were higher than those in methanol or i-propanol. The enhanced lignin depolymerization can be attributed to the excellent in situ hydrogen donating ability of ethanol which is essential for lignin depolymerization. ${ }^{42}$ Cat 2 exhibited superior catalytic

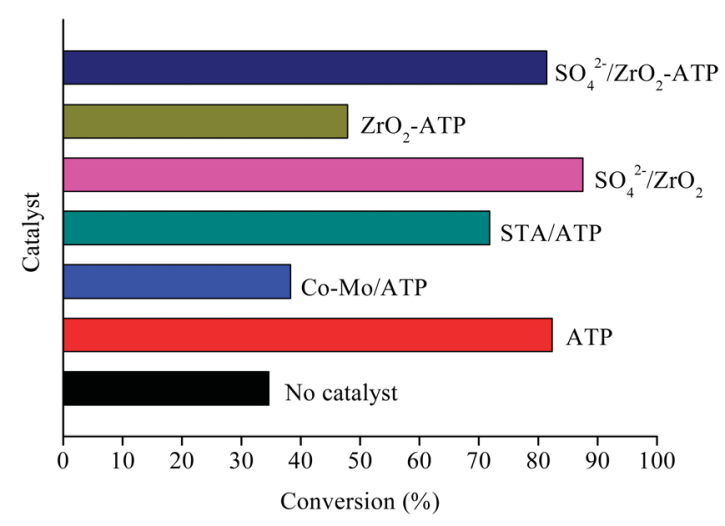

Fig. 2 Conversion of AEL catalyzed by ATP-supported catalysts. selectivity to aromatic esters as compared to the Cat 1 and Cat 3 catalysts, which could be related to the physicochemical properties of the catalysts. Specific surface area and pore size might be the dominant reason. Cat 2 with the smallest specific surface area and the biggest pore size (shown in Table 1) was propitious to the catalytic alcoholysis reaction.

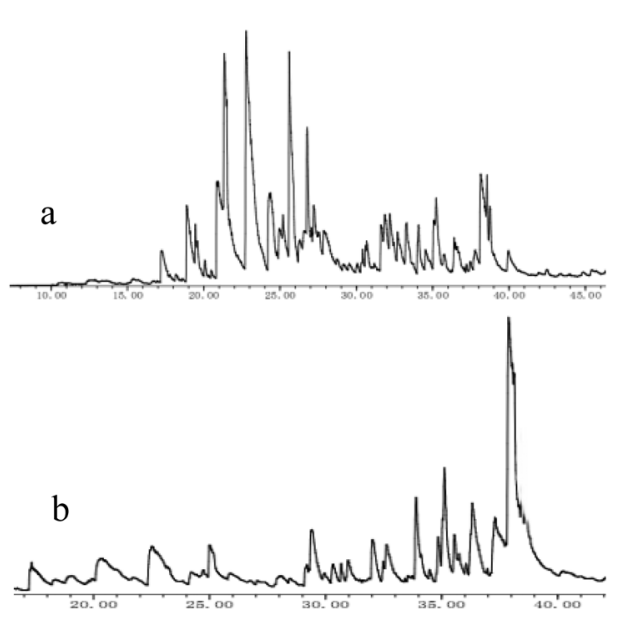

Fig. 3 Total ion chromatogram (TIC) of AEL depolymerization products over no catalyst (a) and $\mathrm{SO}_{4}{ }^{2-} / \mathrm{ZrO}_{2}-\mathrm{ATP}(\mathrm{b})$. 


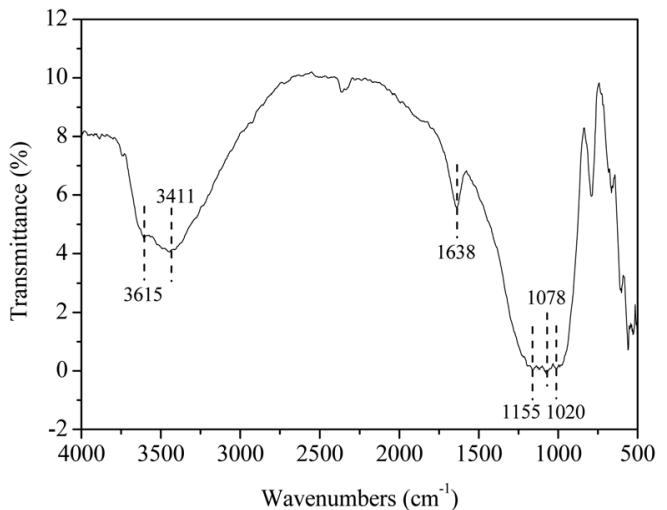

Fig. 4 FTIR spectrum of catalyst $\mathrm{SO}_{4}{ }^{2-} / \mathrm{ZrO}_{2}-\mathrm{ATP}$.

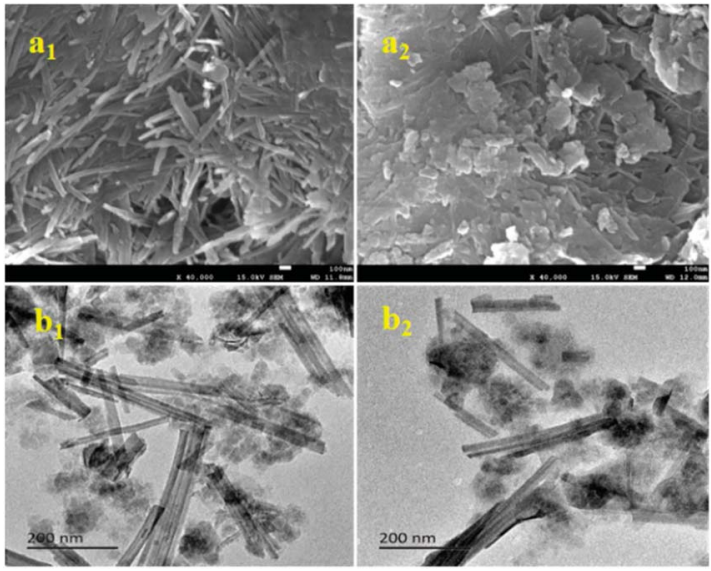

Fig. 5 SEM (a) and TEM (b) images of the original $\left(a_{1}, b_{1}\right)$ and modified $\left(a_{2}, b_{2}\right)$ ATP.

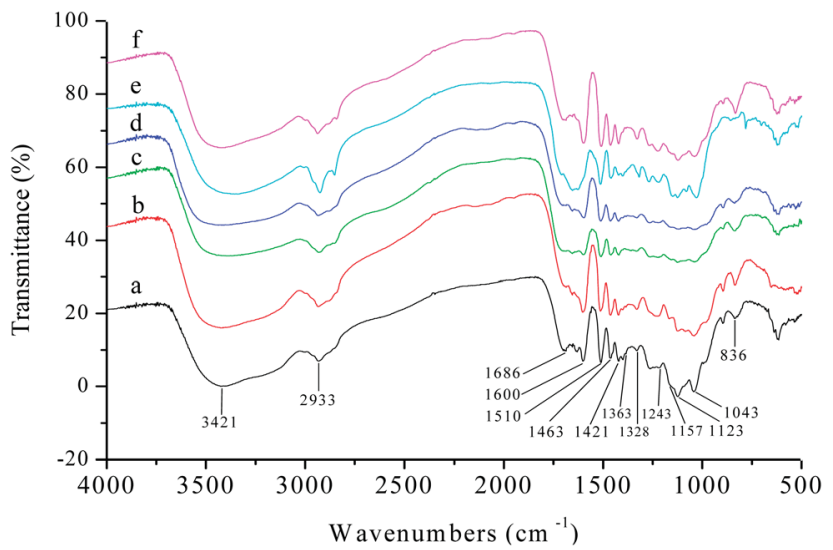

Fig. 6 FTIR spectra of lignin fractions: (a) CCL; (b) CSL; (c) RSL; (d) WSL; (e) PL; (f) BL.

\subsection{Effects of reaction temperature, reaction time, and catalyst loading}

The effects of reaction temperature, reaction time, and catalyst loading on the conversion of AEL of corncob into ethyl ferulate

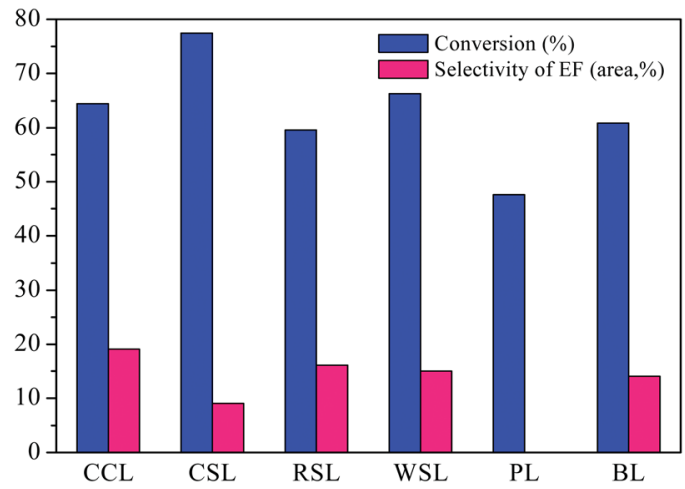

Fig. 7 Different lignin depolymerization catalyzed by $\mathrm{SO}_{4}{ }^{2-} / \mathrm{ZrO}_{2}-$ ATP (Cat 1). Reaction conditions: AEL $(0.5 \mathrm{~g})$, catalyst $(0.25 \mathrm{~g}), \mathrm{C}_{2} \mathrm{H}_{5} \mathrm{OH}$ $(15 \mathrm{~mL}), 225^{\circ} \mathrm{C}, 300 \mathrm{rpm}, 60 \mathrm{~min}$.
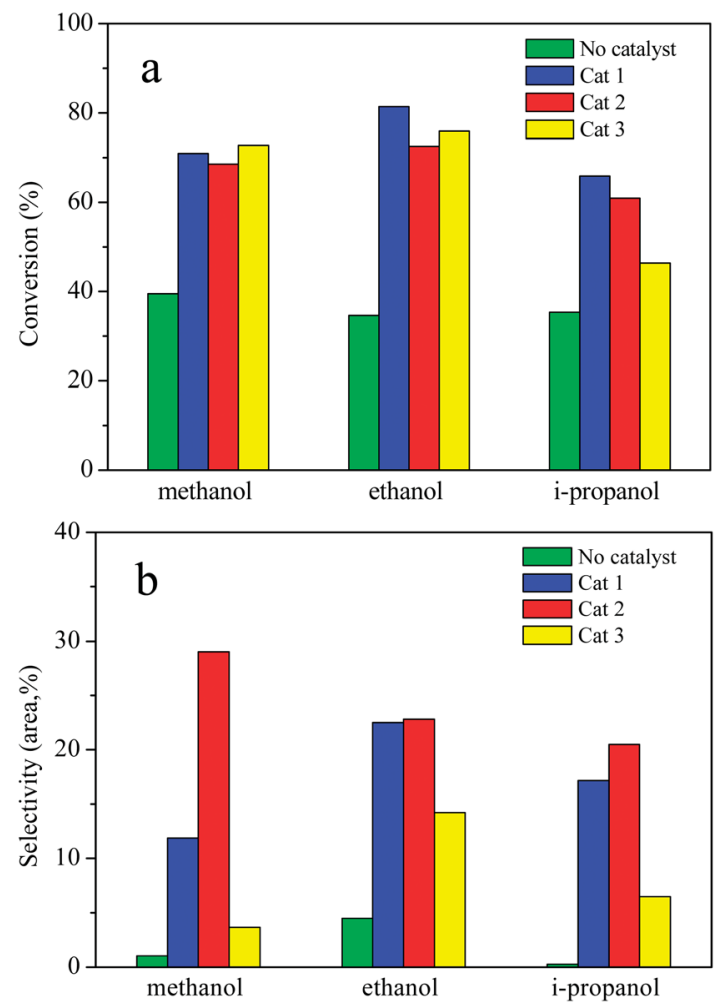

Fig. 8 AEL depolymerization in different alcohol over ATP-supported catalysts. Reaction conditions: AEL $(0.5 \mathrm{~g})$, catalyst $(0.25 \mathrm{~g})$, alcohol (15 $\mathrm{mL}), 225^{\circ} \mathrm{C}, 300 \mathrm{rpm}, 120 \mathrm{~min}$.

were studied. The investigation was conducted in ethanol over Cat 2 and the results were given in Fig. 9. As can be seen, the reaction temperature, reaction time, and catalyst loading have a significant influence on content of ethyl ferulate and lignin conversion. In the case of reaction temperature (Fig. 9(a)), the content of ethyl ferulate and conversion of AEL firstly increased and then decreased progressively with the increase of temperature, and reached highest at $200{ }^{\circ} \mathrm{C}$ (30.5\%) and $225{ }^{\circ} \mathrm{C}$ (81.4\%), respectively. As be seen from Fig. 9(b), the change in AEL conversion with increasing the reaction time could be fitted 
by a quadratic function, with a vertex of $81.4 \%$ at $120 \mathrm{~min}$. It was worth noting that the content of ethyl ferulate changed slightly after $60 \mathrm{~min}$, which indicated that ethyl ferulate produced was more stable to reaction time comparing to reaction temperature. As shown in Fig. 9(c), the content of ethyl ferulate increased substantially from $11.8 \%$ to $28.7 \%$ as the catalyst/AEL ratio increased from $0.1 / 1$ to $1 / 1$, meanwhile, the conversion of AEL increased substantially from $42.3 \%$ to $82.6 \%$, correspondingly. Overall, the dramatic decline of AEL conversion with the increase of temperature, time or catalyst loading was most likely due to the repolymerization of decomposition products or carbonization of carbonaceous materials. Hence, a reaction temperature of $200{ }^{\circ} \mathrm{C}$, a reaction time of $120 \mathrm{~min}$, and
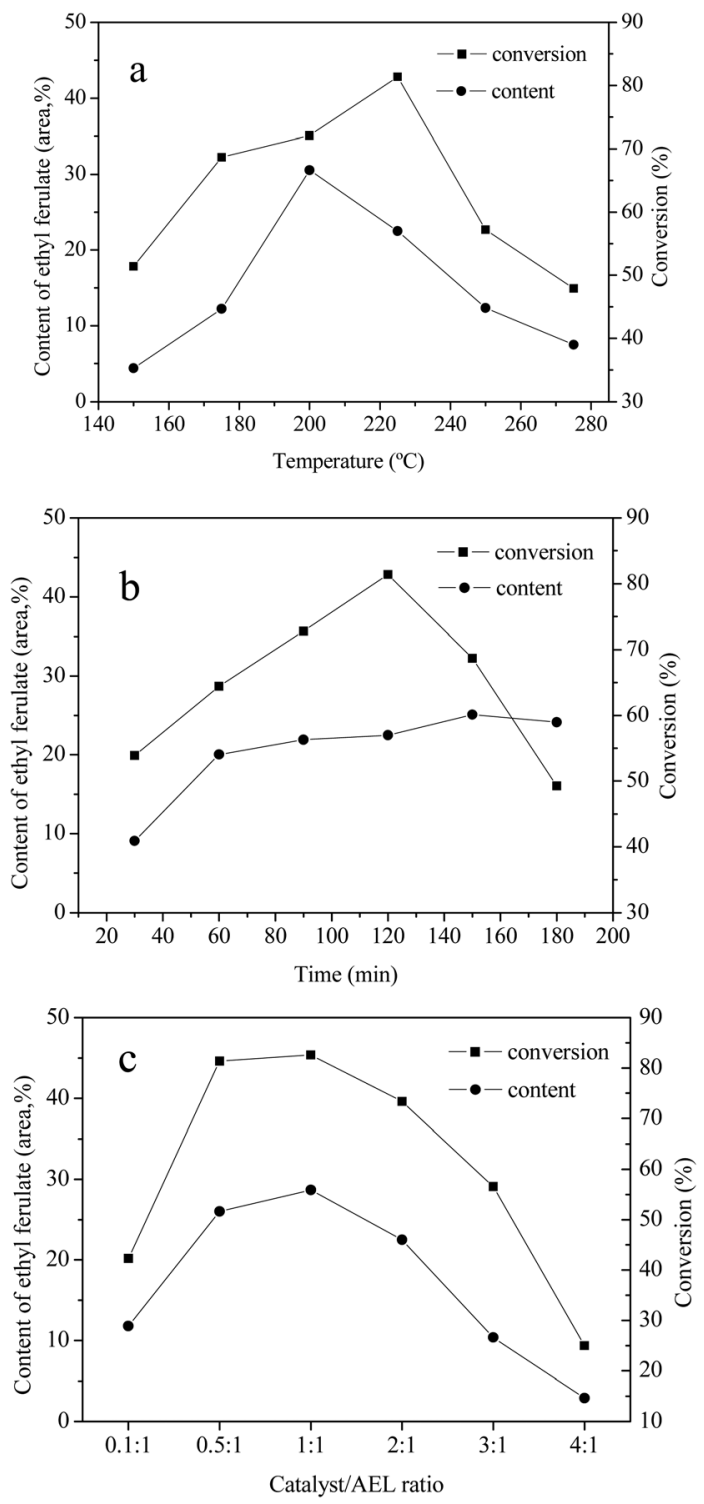

Fig. 9 Effects of reaction temperature $\left(a^{1}\right)$, reaction time $\left(b^{2}\right)$, and catalyst loading $\left(c^{3}\right)$ on AEL depolymerization. ${ }^{1}$ Reaction conditions: catalyst $(0.25 \mathrm{~g}), \mathrm{AEL}(0.5 \mathrm{~g}), \mathrm{C}_{2} \mathrm{H}_{5} \mathrm{OH}(15 \mathrm{~mL}), 300 \mathrm{rpm}, 120 \mathrm{~min}$. ${ }^{2}$ Reaction conditions: catalyst $(0.25 \mathrm{~g}), \mathrm{AEL}(0.5 \mathrm{~g}), \mathrm{C}_{2} \mathrm{H}_{5} \mathrm{OH}(15 \mathrm{~mL})$, $225^{\circ} \mathrm{C}, 300 \mathrm{rpm} .{ }^{3}$ Reaction conditions: AEL $(0.5 \mathrm{~g}), \mathrm{C}_{2} \mathrm{H}_{5} \mathrm{OH}(15 \mathrm{~mL})$, $225^{\circ} \mathrm{C}, 300 \mathrm{rpm}, 120 \mathrm{~min}$. a catalyst/AEL ratio of $1: 1$ were chosen as the optimal conditions for the conversion of AEL into ethyl ferulate.

\subsection{Catalyst stability}

The reusability or recyclability of the catalyst is an important parameter for the evaluation of heterogeneous catalyst. In this paper, repetitive use of the catalyst $\mathrm{SO}_{4}{ }^{2-} / \mathrm{ZrO}_{2}$-ATP (Cat 2) was performed to test its stability. The stability was investigated by the depolymerization of AEL and evaluated by conversions of AEL and relative contents of main esters (compounds 10-15, area, \%) in decomposition products. The details of the reusability test were as follows: $0.5 \mathrm{~g}$ of catalyst, $0.5 \mathrm{~g}$ of AEL, and $15 \mathrm{~mL}$ of ethanol were loaded into the reactor, $200{ }^{\circ} \mathrm{C}$ for $120 \mathrm{~min}$. After the depolymerization reaction, the resulting products were carefully poured out and filtered for the reuse of the catalyst in the reactor, weighed and calculated the weight loss as conversion. Fresh AEL was then added and the process was repeated under the same conditions. This procedure was repeated 8 times. The results of the recycle experiments are shown in Fig. 10. It can be seen that $\mathrm{SO}_{4}{ }^{2-} / \mathrm{ZrO}_{2}$-ATP kept a good catalytic activity for the conversion of AEL and a 78.6\% conversion of AEL and a $29.4 \%$ selectivity of ethyl ferulate were achieved after 1 run under the optimal conditions of $200{ }^{\circ} \mathrm{C}$, $120 \mathrm{~min}$, and catalyst/AEL ratio of $1: 1$. Conversion of $65.3 \%$ was still achieved after 6 runs. Meanwhile, the total relative contents of main esters decreased from $49.5 \%$ to $27.6 \%$ and $18.3 \%$ after 6 and 8 runs, respectively, which indicated that the catalyst could be reused at least 6 times. We also noticed that the distribution of esters experienced great changes after the repetitive use of the catalyst. Nearly all the contents of main esters decreased significantly and some even disappeared, which could be attributed to the deterioration of catalytic capacity of the used catalyst.

\subsection{Mechanism analysis}

Based on the major products observed in Table 2 , a $\beta-O-4$ model compound, 3-(4-hydroxy-3-methoxyphenyl)-3-hydroxy-

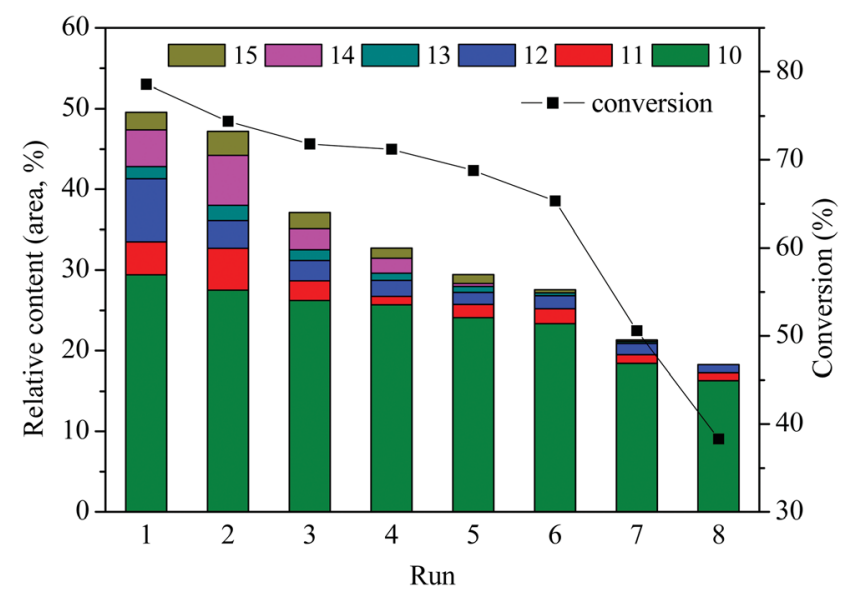

Fig. 10 Repeated use of catalyst $\mathrm{SO}_{4}{ }^{2-} / \mathrm{ZrO}_{2}-\mathrm{ATP}$ in the depolymerization of AEL. 
2-(2-methoxyphenoxy) propionic acid, was depolymerized in ethanol under the reaction conditions. As a result, compounds $2,3,4,10,11,12$, and 18 in Table 2 were detected in the model depolymerization products, indicating that the model could explain the basic structure of AEL well. Based on the above analysis, the authors proposed some possible reaction mechanism of depolymerization of AEL catalyzed by $\mathrm{SO}_{4}{ }^{2-} / \mathrm{ZrO}_{2}{ }^{-}$ ATP in ethanol and the possible pathways are summarized in Fig. 11. Given that the $\beta-O-4$ bond cleavage (cleavage 3 ) happened initially at relatively low temperature under acid conditions because of its low dissociation energy. ${ }^{\mathbf{4 3 4 4}}$ Aldehydes and phenols (guaiacol, 4-ethylphenol, and 4-ethyl-2methoxyphenol) were generated by $\beta-O-4$ bond cleavages and hydrogenation reaction that probably initiated by hydrogen radicals produced by ethanol. Acids and ketones might be produced by hydrogenation and dehydrogenation reaction. Being the most abundant products, aromatic esters, including ethyl 4-hydroxy-3-methoxycinnamate (compound 10), ethyl 3(4-hydroxy-3-methoxyphenyl) propionate (compound 11), and methyl 4-hydroxy-3-methoxyphenylacetate (compound 12) (marked with red), could be produced by $\beta-O-4$ bond cleavages and reactions of esterification, hydrogenation, and dehydration over $\mathrm{SO}_{4}{ }^{2-} / \mathrm{ZrO}_{2}$-ATP in ethanol, among which esterification reaction between ethanol and lignin-derived intermediates, such as ferulic acid and phenylacetic acid formed during lignin depolymerization was the main contributor. In another way, aromatic esters might be generated by the transesterification reaction between ethanol and covalent linkages which connect lignin with cellulose or hemicellulose in the form of lignin-ether bond-phenolic acidester bond-hemicellulose or lignin-ester bond-phenolic acid. ${ }^{45}$

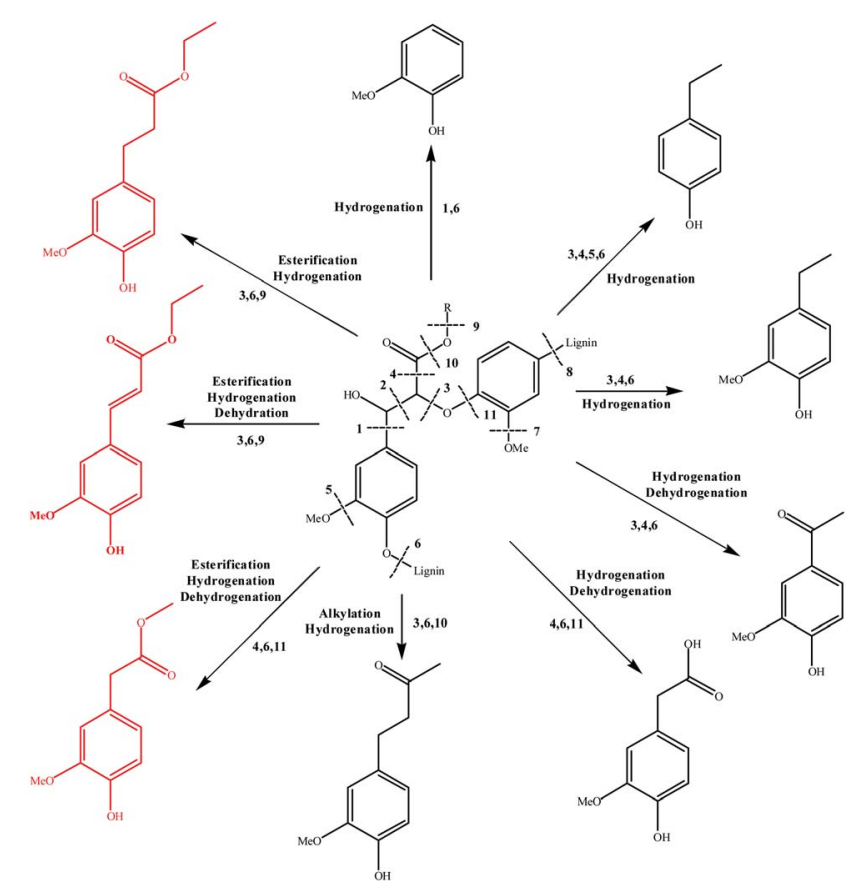

Fig. 11 Proposed reaction pathway of AEL depolymerization catalyzed by $\mathrm{SO}_{4}{ }^{2-} / \mathrm{ZrO}_{2}-$ ATP in ethanol.
These results indicated that ethanol served as not only a solvent but also a reactant for the depolymerization of AEL over $\mathrm{SO}_{4}{ }^{2-} / \mathrm{ZrO}_{2}$-ATP.

\section{Conclusion}

The depolymerization of AEL in alcohols over ATP-supported catalysts was investigated. Among all ATP-supported catalysts prepared, $\mathrm{SO}_{4}{ }^{2-} / \mathrm{ZrO}_{2}$-ATP with excellent catalytic activity and catalytic selectivity was selected. Herbaceous lignin was found to be more suitable for the preparation of aromatic esters from AEL due to the composition of the lignin fraction and the contents of phenolic acids. Ethanol presented the highest alcoholysis ability was selected as the alcohol solvent. A 78.6\% conversion of AEL of corncob and a $29.4 \%$ selectivity to ethyl ferulate were achieved under the optimal conditions of $200{ }^{\circ} \mathrm{C}$, $120 \mathrm{~min}$, and catalyst/AEL ratio of $1: 1$ over Cat 2 . The catalyst could be used at least 6 successive runs with a decline from $78.6 \%$ to $65.3 \%$ in the conversion of AEL and a decline from $49.5 \%$ to $27.6 \%$ in main esters relative content. Ethanol was found to be not only a solvent but also a reactant for the depolymerization of AEL over $\mathrm{SO}_{4}{ }^{2-} / \mathrm{ZrO}_{2}$-ATP.

\section{Conflicts of interest}

There are no conflicts to declare.

\section{Acknowledgements}

The authors are grateful for financial support from the National Key Research and Development Plan of China (2016YFD0600801), the Priority Academic Program Development of Jiangsu Higher Education Institutions (PAPD), as well as Top-notch Academic Programs Project of Jiangsu Higher Education Institutions (TAPP).

\section{References}

1 S. H. Ghaffar and M. Fan, Int. J. Adhes. Adhes., 2014, 48, 92101.

2 A. K. Deepa and P. L. Dhepe, ACS Catal., 2015, 5, 365-379.

3 J. Y. Kim, J. H. Lee, J. Park, J. K. Kim, D. An, I. K. Song and J. W. Choi, J. Anal. Appl. Pyrolysis, 2015, 114, 273-280.

4 Z. Cai, Y. Li, H. He, Q. Zeng, J. Long, L. Wang and X. Li, Ind. Eng. Chem. Res., 2015, 54, 11501-11510.

5 R. Behling, S. Valange and G. Chatel, Green Chem., 2016, 18, 1839-1854.

6 S. Y. Park, C. Y. Hong, H. S. Jeong, S. Y. Lee, J. W. Choi and I. G. Choi, J. Anal. Appl. Pyrolysis, 2016, 121, 113-120.

7 M. K. Chan, Q. Ye, Z. M. Png, H. N. Zeng, X. Wang and J. Xu, Waste Biomass Valorization, 2016, 1-8.

8 G. Zhu, X. Qiu, Y. Zhao, Y. Qian, Y. Pang and X. Ouyang, Bioresour. Technol., 2016, 218, 718-722.

9 P. Chen, Q. Zhang, R. Shu, Y. Xu, L. Ma and T. Wang, Bioresour. Technol., 2016, 226, 125-131.

10 F. Yan, R. Ma, X. Ma, K. Cui, K. Wu, M. Chen and Y. Li, Appl. Catal., B, 2017, 202, 305-313. 
11 M. J. Hidajat, A. Riaz, J. Park, R. Insyani, D. Verma and J. Kim, Biochem. Eng. J., 2017, 317, 9-19.

12 J. Y. Kim, J. Park, H. Hwang, J. K. Kim, I. K. Song and J. W. Choi, J. Anal. Appl. Pyrolysis, 2015, 113, 99-106.

13 S. Hu, F. Jiang and Y. L. Hsieh, ACS Sustainable Chem. Eng., 2015, 3, 2566-2574.

14 V. N. Bui, D. Laurenti, P. Afanasiev and C. Geantet, Appl. Catal., B, 2011, 101, 239-245.

15 H. Y. Zhao, D. Li, P. Bui and S. T. Oyama, Appl. Catal., A, 2011, 391, 305-310.

16 E. Lam and J. H. T. Luong, ACS Catal., 2014, 4, 3393-3410.

17 A. L. Jongerius, R. W. Gosselink, J. Dijkstra, J. H. Bitter, P. C. A. Bruijnincx and B. M. Weckhuysen, Chemcatchem, 2013, 5, 2964-2972.

18 Y. Zheng, D. Chen and X. Zhu, J. Anal. Appl. Pyrolysis, 2013, 104, 514-520.

19 X. Liu, L. Xu, G. Xu, W. Jia, Y. Ma and Y. Zhang, ACS Catal., 2016, 6, 7611-7620.

20 R. Giustetto, J. G. Vitillo, I. Corazzari and F. Turci, J. Phys. Chem. C, 2014, 118, 19322-19327.

21 B. Yuan, X. Q. Yin, X. Q. Liu, X. Y. Li and L. B. Sun, ACS Appl. Mater. Interfaces, 2016, 8, 16457-16464.

22 H. Yang, A. Tang, J. Ouyang, M. Li and S. Mann, J. Phys. Chem. B, 2010, 114, 2390-2398.

23 S. Miao, Z. Liu, Z. Zhang, B. Han, Z. Miao, K. Ding and G. An, J. Phys. Chem. C, 2007, 111, 2185-2190.

24 K. Nagaoka, K. Seshan, J. A. Lercher and K. I. Aika, Catal. Lett., 2000, 70, 109-116.

25 L. Grzona, N. Comelli, O. Masini, E. Ponzi and M. Ponzi, React. Kinet. Catal. Lett., 2000, 69, 271-276.

26 E. Hernández-Ramírez, J. A. Wang, L. F. Chen, M. A. Valenzuela and A. K. Dalai, Appl. Surf. Sci., 2017, 399, 77-85.

27 F. Rahmani, M. Haghighi and B. Mohammadkhani, Microporous Mesoporous Mater., 2017, 242, 34-49.
28 R. Dong, Y. Liu, X. Wang and J. Huang, J. Chem. Eng. Data, 2011, 56, 3890-3896.

29 M. Ferrari, B. Delmon and P. Grange, Carbon, 2002, 40, 497511.

30 M. V. Bykova, D. Y. Ermakov, V. V. Kaichev, O. A. Bulavchenko, A. A. Saraev, M. Y. Lebedev and V. A. Yakovlev, Appl. Catal., B, 2012, 113-114, 296-307.

31 S. Zhang, L. Su, L. Liu and G. Fang, Ind. Crops Prod., 2015, 77, 451-457.

32 H. Yan, Y. Yang, D. Tong, X. Xiang and C. Hu, Catal. Commun., 2009, 10, 1558-1563.

33 K. Hashizume, T. Ito, T. Ishizuka and N. Takeda, J. Biosci. Bioeng., 2013, 116, 209-213.

34 M. D. Horbury, L. A. Baker, N. D. N. Rodrigues, W. D. Quan and V. G. Stavros, Chem. Phys. Lett., 2017, 673, 62-67.

35 P. Pushpaletha and M. Lalithambika, Appl. Clay Sci., 2011, 51, 424-430.

36 H. Ma, K. Sun, Y. Li and X. Xu, Catal. Commun., 2009, 10, 1363-1366.

37 H. Chen, A. Zhong, J. Wu, J. Zhao and H. Yan, Ind. Eng. Chem. Res., 2012, 51, 14026-14036.

38 B. Wang, J. Zhu and H. Ma, J. Hazard. Mater., 2009, 164, 256264.

39 S. Nanayakkara, A. F. Patti and K. Saito, ACS Sustainable Chem. Eng., 2014, 2, 2159-2164.

40 X. P. Peng, S. L. Sun, J. L. Wen, W. L. Yin and R. C. Sun, Fuel, 2014, 134, 485-492.

41 N. Kumar and V. Pruthi, Biotechnol. Rep., 2014, 4, 86-93.

42 K. Cui, L. Yang, Z. Ma, F. Yan, K. Wu, Y. Sang, H. Chen and Y. Li, Appl. Catal., B, 2017, 219, 592-602.

43 W. Mu, H. Ben, A. Ragauskas and Y. Deng, BioEnergy Res., 2013, 6, 1183-1204.

44 S. Chu, A. V. Subrahmanyam and G. W. Huber, Green Chem., 2013, 15, 125-136.

45 X. Zhang, W. Yang and W. Blasiak, Energy Fuels, 2011, 25, 4786-4795. 